American Journal of

Health, Medicine and Nursing Practice (AJHMN)

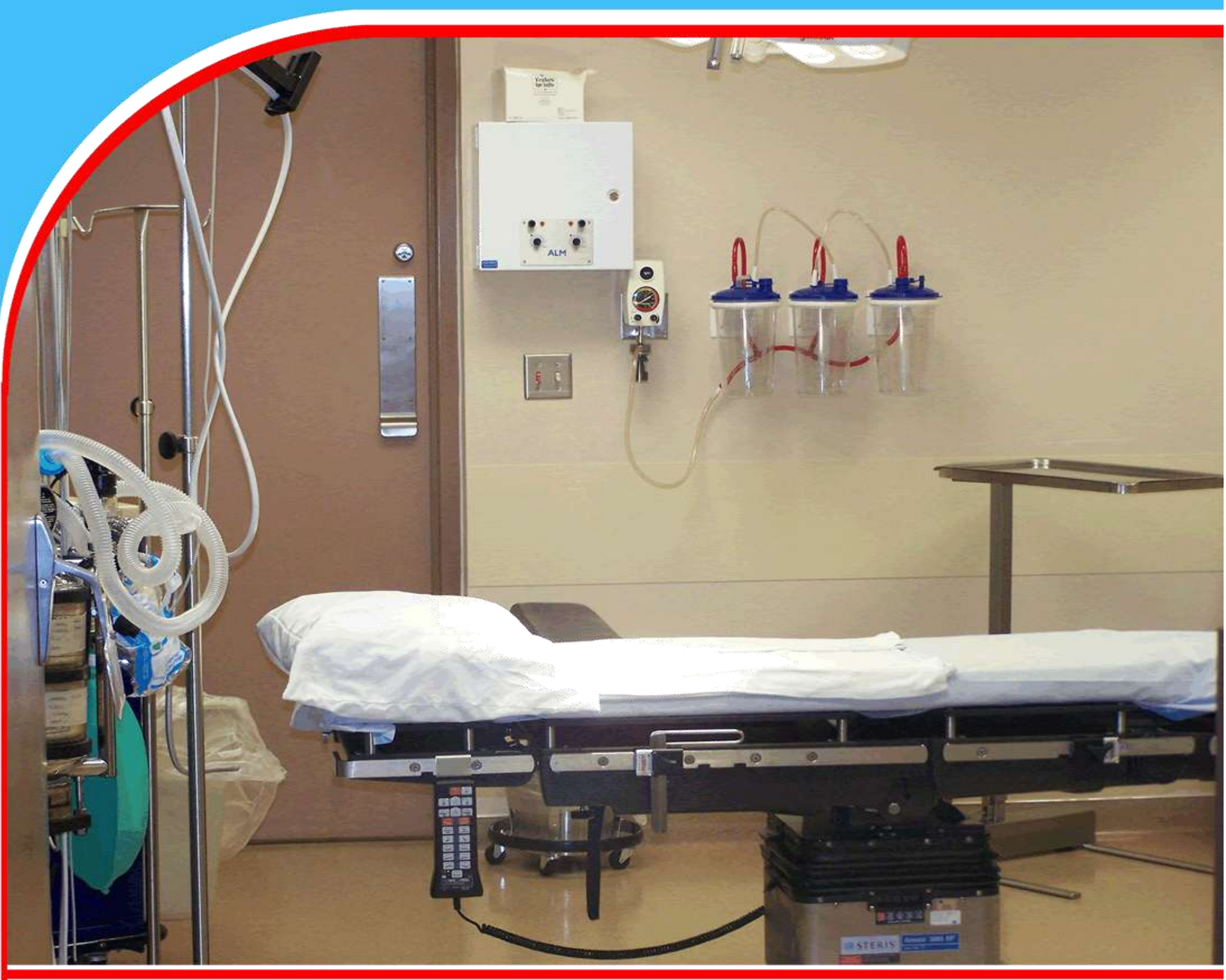

LIVED EXPERIENCES OF WOMEN WITH GYNECOLOGICAL CANCERS ATTENDING TEACHING HOSPITALS IN EKITI STATE.

Oluwabukola Ayo Gentry Christiana Olanrewaju Sowunmi

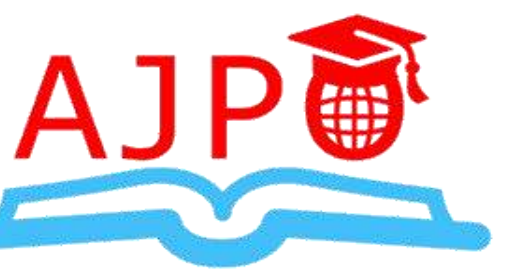




\title{
LIVED EXPERIENCES OF WOMEN WITH GYNECOLOGICAL CANCERS ATTENDING TEACHING HOSPITALS IN EKITI STATE.
}

\author{
1*Oluwabukola Ayo Gentry \\ School of Nursing, Babcock University \\ Ilisan-remo, Ogun State \\ Nigeria \\ E-mail: oluwabukolagentry@gmail.com \\ ${ }^{2}$ Christiana Olanrewaju Sowunmi \\ Dean, School of Nursing, Babcock University \\ Ilisan-remo, Ogun State \\ Nigeria \\ Email: lanresowunmi@hotmail.com
}

\begin{abstract}
Purpose: The purpose of this study was to explore the lived experiences of women with gynecological cancers attending teaching hospitals in Ekiti State.

Methodology: A qualitative research design was used using a phenomenological method. Twenty women with gynecological cancers were recruited for the study using purposive sampling. The research instrument was a structured interview guide. The interviews were conducted once and recorded using a digital voice recorder and basic demographic information of respondents was obtained after each interview. The interview transcripts were analyzed using thematic analysis and major themes emerged from the study, while the demographic information was analyzed using descriptive statistics.

Findings: Results from this study identified nine major themes which include ignoring the initial warning signs, reliance on unprofessional help and spiritual interventions, feeling of uncertainty and sense of vulnerability, bodily changes and altered body image, the burden of chemotherapy, financial hardship, counting the losses, dealing with community and family-based stigma and then cancer as a spiritual attack. This study therefore recommends the need to address individual perceptions about the causes of gynecological cancers as well as the need to draw a supportive intervention by the government for affected persons.
\end{abstract}

Keywords: Chemotherapy, Gynecological Cancers, Lived Experiences, Persons, Teaching Hospitals 


\subsection{INTRODUCTION}

Lived experiences of persons with gynecological cancers are such that cannot be overlooked owing to barrages of disturbing moments that accompany the nature of the illness. The experiences of individuals with gynecological cancers often projects struggles that makes it burdensome for them to bridge the gap between the ability to measure up with personal demands and fulfillment of their life's expectation. While some persons may receive the diagnosis of a gynecological cancer as a death sentence which may leads to poor health seeking behaviors, other persons are sometimes be-clouded by superstitious believes which make them seek alternative care. All these worsen the lived experiences of persons with gynecological cancers.

According to the Global Cancer Observatory report of 2018, new cases of gynecological cancers account for two million, eighty eight thousand, eight hundred and forty nine $(2,088,849)$ and five hundred and sixty nine thousand eight hundred and forty seven $(569,847)$ respectively while the number of death are Six hundred and twenty six thousand, six hundred and seventy nine $(626,679)$ and three hundred and eleven thousand three hundred and sixty five $(311,365)$ per year worldwide. Gynecological cancer accounts for more than $12 \%$ of all female cancers with increase both in incidence and survival in all groups in the Nordic countries (Sekse, Dunberger, Olense, Sterbye\& Seibaek, 2018).

Africans diagnosed with gynecological cancers often face many challenges associated with cancer itself, cancer treatments and their health effects, cultural understandings, social and spiritual concerns, and financial constraints, among others. Their lived experience is thus compromised preventing them from being able to fully engage in meaningful life endeavors (Rhoda, Suubi, Anna \& Beverly, 2016). Another study revealed that females with gynecological cancers are faced with physical, psychological and social distress in addition to fatigue, irritability, memory loss, decreased energy level, recurring pain and decreased lived experience (Huei-Ying, Wen-chen, Wen-Yu, Yao-ching, Liang-chih et.al. 2017).

Although the survival rate of gynecological cancer patients has increased by at least 5 years in developing countries, the side effects of chemotherapy result in a relatively constant alteration in the body functions of survivors (Abdolghani, Mohammaddreza \& Mahin, 2018). Cervical cancer caused 8.1 million disability-adjusted life years, with $96 \%$ coming from years of life lost and $4 \%$ from years lived with disabilities (Fitzmaurice, 2019).

Females living with gynecological cancers are faced with physical, psychological and social distress in addition to fatigue, irritability, memory loss, decreased energy level, recurring pain and decreased lived experience as a result of symptom distress experienced by cancer survivors which is a critical factor influencing their lived experience (Huei-Ying et.al. 2017).

\subsection{Statement of the Problem}

Six hundred and one thousand women developed a major gynecological cancer worldwide which led to 260,000 deaths (Fitzmaurice, 2019). There were an estimated 266,000 deaths from cervical cancer worldwide in 2012, accounting for $7.5 \%$ of all female cancer deaths. Almost nine out of ten $(87 \%)$ cervical cancer deaths occur in the less developed regions. The American Cancer Society's estimates for cervical cancer in the United States of America for 2018 are about 13,240 
American Journal of Health, Medicine and Nursing Practice

ISSN 2520-4017 (Online)

Vol.6, Issue 3, pp 1 - 24, 2021

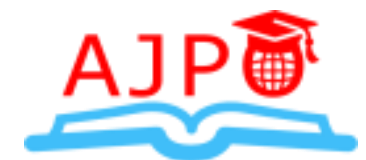

www.ajpojournals.org

new cases of invasive cervical cancer and about 4170 women will die from cervical cancer (Farghaly, 2019).

Cervical cancer is the second most common cancer among women living in low and middleincome countries. Estimated 100,000 women are diagnosed annually with cervical cancer in Sub-Saharan Africa. Without treatment, 62 percent of these women would be expected to die from the disease. In 2018, there were an estimated 570000 new cases of cervical cancer and 311 000 deaths from it worldwide. Cervical cancer is a disease fuelled by social, economic and political inequities. Lower-income countries bear the highest burden, with nearly $80 \%$ of all cervical cancers and $90 \%$ of deaths. Nine out of 10 women who die from cervical cancer live in low- and middle-income countries (UNAIDS, 2018; 2019).

In 2018, around 311000 women died of cervical cancer, $85 \%$ of whom were in low- and middleincome countries, where vaccination, screening and treatment programs are limited. Around $70 \%$ of women who develop cervical cancer require radiotherapy to effectively treat the disease; however (UNAIDS, 2020).

Going by the account of the National Cancer Incidence based on Population based Registries Data (2013), gynecological cancers account for the highest new cases in Ekiti state with breast cancer constituting eight hundred and seventy one (871) and cervical cancer having about two hundred and ninety (290) cases per 100,000 respectively, while at the Federal Teaching Hospital, Ido-Ekiti, gynecological cancers accounts about seventy percent $(66.9 \%)$ of overall cancer cases reported on a yearly basis.

The disease process of cancer, its treatment, and side effects of treatment results in remarkable distress among persons with gynecological cancer and their family caregiver in physical, psychological, social and spiritual domains (Sharma, Saneha \& Philigbua, 2021).

Going by the account of Guenther, Stiles and Champion (2015), some women described their experiences as a phenomenon of uncoordinated actions. The uniqueness of some of their experiences was that they experienced total exhaustion that was not relieved with rest. It wssas reported that years after gynecological cancer, women have to deal with fundamental changes and challenges concerning their physical, mental and psychosocial well-being (Sekse et.al, 2018).

Therefore, this study aimed to explore the lived experiences of women with gynecological cancers attending Teaching Hospital in Ekiti state using a phenomenological approach.

\subsection{Objective of the Study}

The objective of the study was to explore the lived experiences of women with gynecological cancers attending Teaching Hospitals in Ekiti State Nigeria. 
American Journal of Health, Medicine and Nursing Practice

ISSN 2520-4017 (Online)

Vol.6, Issue 3, pp 1 - 24, 2021

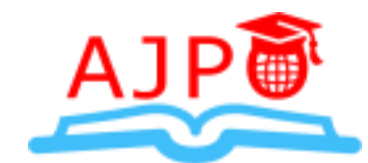

www.ajpojournals.org

\subsection{LITERATURE REVIEW}

\subsubsection{Theoretical Framework}

This study adapted the Danish philosophy of good quality of life propounded in the $19^{\text {th }}$ century by Kierkegaard, a Danish philosopher who was a major influence on existentialism and Protestant theology propounded in the 19th century. He opined that life philosophy seeks answers to existential issues like the meaning of a human life, and what it entails to live "a good quality of life". As humans we ask ourselves such questions at some point. One may say that we search for our own life philosophy, more or less consciously, based on our own experiences. When a crisis like a serious illness occurs, existential questions are vitalized in new ways that may influence our ways of living.

Danish life philosophy is further explored by Pahuus (1993) that life itself fathoms the main thoughts of life philosophy explained by distinguishing between two human activities; the drive to satisfy needs and the fulfillment of needs. The needs reveal themselves as individually and socially formed desires and expectations that can be satisfied by targeted actions. Needs are expressions of something lacking and may be experienced as something missing or longed for, a longing not necessarily founded on the absence of something. The fulfillment of needs does not necessarily result in satisfaction, but in something more comprehensive. Life fulfillment entails feelings of being alive, of life courage, of a sense of coherence and joy for life itself (phenomena touching deeper dimensions of life). These needs can be called an ethical or existential life phenomenon.

Life crises, such as serious illness and loss, are part of human life, unavoidable in any person's lifetime. In this study, persons who have experienced gynecological cancers have varying needs which have challenged them to take hold of their lives in new ways, the satisfaction of these needs leads to good quality of life. The Danish philosophy of good quality of life is considered useful in order to gain a deeper understanding of this life-changing process.

\subsubsection{Empirical review}

The disease process of cancer, its treatment, and side effects of treatment results in remarkable distress among persons with gynecological cancer (Sharma, Saneha \& Philigbua, 2021). Women with gynecological cancers experienced several side effects resulting from treatment therapies such as surgery, chemotherapy, and radiotherapy. Common side effects reported by the women included hot flashes, vaginal dryness, diminished libido, sexual dysfunction, and depression (Muliira, Salas \& O’Berien, 2017). Cervical cancer comes with physical disruption that takes a toll in the bodies of persons affected by it. Most women reported further disruptions to their physical body in terms of body pains, cessation of sexual activity, loss of appetite, immobility and loss of sleep. The physical disruption women experienced spanned across symptomatic, diagnosis, treatment and post treatment periods (Binka, Doku \& Awusabo-Asare, 2017).

Certain sequel can persist or periodically arise for some individual with gynecological cancers which often made them experience "islands" of psychosocial disruption. The physical implications of the gynecological cancer treatment are framed by a strong perception of having a changed female body. These changes occur in a time span from immediately after the treatment 
to decades hereafter (Annette \& Patricia, 2015; Sekse et al., 2018). The psychological problems found in most women with gynecological cancers included frustration and despair, depression, inability to control anger, disruption in body image, and problems with their sex lives. All these problems sometimes result in thoughts and feelings of frustration (Yaman \& Ayaz, 2016).

Most women experienced psychological disruption in four phases: when they saw the disease symptoms, when they received diagnosis, during treatment and after treatment. These disruptions were clustered into three areas; namely, negative emotions, fear of death and anxiety. Some became sad and fearful when they noticed the symptoms of the disease. Some of the women also felt sad that something as embarrassing as that was happening to them (Binka, Doku \& Awusabo-Asare, 2017). Worry that cancer may return after treatment is among the most commonly experienced issues coupled with the fact that increased fear of recurrence is related to survivors' higher use of healthcare services as well as poorer lived experiences in survivors and their caregivers (Annette \& Patricia, 2015; Huei-Ying, Wen-Chen, Wen-Yu, Yao-Ching, LiangChih \& Kuo-Feng, 2017).Women have to deal with fundamental changes and challenges concerning their psychosocial well-being years after gynecological cancer (Sekse et al. 2018).

Muliira et al. (2017) reported in her study that certain women who had gynecological cancers had very little psychosocial support and scored very low on the quality of life tools in the psychological domain. In addition, low psychosocial support was expressed in lower scores for social functioning. Low psychosocial support was mostly reported among women who were not formally employed and those with lower income such as peasant farmers and casual workers. Further, lower psychosocial support was reported among patients who had no family caregivers involved in their routine clinical care subsequently, leading to poor psychosocial support and poor lived experience. Social exclusion is a major challenge faced by women who are diagnosed with gynecological cancers owing to varying traditional cultural mores that foster an impression that these women are defective (Li-Yun et.al. 2017; Yaman \& Ayaz, 2016).

Break-up of social relationships was one of the experiences of persons who had gynecological cancers. Some women explained that their partners deserted them while other women also had disrupted relationship with their siblings which later led to abandonment. Some of them reported that their partners left them because they could no longer endure having sex with them. Category of persons in these groups felt disappointed without the emotional support of their partners during their treatment (Binka, Doku \& Awusabo-Asare, 2017). A qualitative study exploring psychosocial distress, coping and social support among women with ovarian cancer reported that when the participants were asked who they thought would be most beneficial to talk to about their experiences of cancer, most women responded that another survivor would be the best (Mattsson, Ljungman, Einhorn, Poromaa, Stålberg \& Wikman, 2020).

The importance of being supported by family and friends, especially partners/spouses, was a critical factor for well-being. Some individuals experienced changes in their relationships. Time spent with family was reduced due to treatment demands and withdrawal of loved ones from them. All participants agreed that relationships with their family and friends influenced their lives. Some participants spoke of experiencing lack of support with unpredictable reactions and withdrawal of family and/or friends. Other participants spoke of being avoided and noticed that 
American Journal of Health, Medicine and Nursing Practice

ISSN 2520-4017 (Online)

Vol.6, Issue 3, pp 1 - 24, 2021

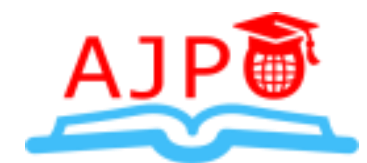

www.ajpojournals.org

people around them "react differently" which then created emotional reactions such as upset and insecurity (Bobans, Downs, Codde, Cohen \& Bulsara, 2021).

\subsection{RESEARCH METHODOLOGY}

A qualitative research design was used using a phenomenological method. The study inclusion criteria were all persons with gynecological cancers who were on follow-up visit at the Ekiti State University Teaching Hospital, Ado Ekiti and Federal Teaching Hospital, Ido-Ekiti. Persons that were still on chemotherapy, persons who were not willing to participate in the study and those who could not give consent for severity of their health status were excluded from the study. A purposive sampling method was used to recruit the respondents from the two teaching hospitals, as respondents were selected based on the inclusion criteria. Within each facility, individual interview were conducted on eligible persons that volunteered to participate. A total of 20 respondents were interviewed until data saturation was attained. The research instrument was a structured interview guide. The interviews were conducted once and recorded using a digital voice recorder and basic demographic information of respondents was obtained after each interview. All recorded data were transcribed into Microsoft word 10and translated from Yoruba to the English language before they were imported into computer software for qualitative data analysis (NVivo version 12). After transcription, the researcher listened to the audio recordings separately and compared them with the transcribed texts to ascertain the accuracy of data. Each transcript was read several times line by line. Descriptors from the words of respondents that described the phenomenon of interest were identified to generate codes and categories. Data categories were reviewed to discover recurrent patterns of meanings which were then grouped as major themes, while the demographic information was analyzed using descriptive statistics.

\subsection{PRESENTATION OF FINDINGS, ANALYSIS AND INTERPRETATION}

Thematic analysis of data collected on the lived experiences of persons with gynecological cancers attending the teaching hospitals in Ekiti State. The findings are also discussed in the light of previous research findings and available literature, where applicable, to identify similarities and differences between this study and previous studies and literature. A total of twenty respondents participated in the study. Socio demographic data of the respondents were collected, and individual interviews were done. A total of nine (9) themes emerged from this study. 
American Journal of Health, Medicine and Nursing Practice

ISSN 2520-4017 (Online)

Vol.6, Issue 3, pp 1 - 24, 2021

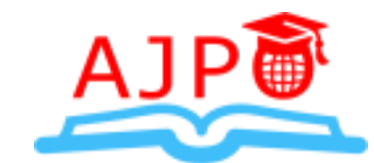

www.ajpojournals.org

Data Analysis and Results

Sociodemographic data of Persons with Gynecological Cancers attending Teaching Hospitals in Ekiti State

Table 4.1 Socio-demographic data of Persons with Gynecological Cancers attending Teaching Hospitals in Ekiti State

\begin{tabular}{|c|c|c|c|c|c|c|c|}
\hline Respondents & Age & Religion & $\begin{array}{l}\text { Marital } \\
\text { status }\end{array}$ & $\begin{array}{l}\text { Educational } \\
\text { level }\end{array}$ & $\begin{array}{l}\text { Employment } \\
\text { status }\end{array}$ & $\begin{array}{l}\text { Cancer } \\
\text { type }\end{array}$ & Duration \\
\hline 1 & 46 & Islam & Married & Pry. Six & $\begin{array}{l}\text { Self- } \\
\text { employed }\end{array}$ & Breast & Over 2 years \\
\hline 2 & 36 & Christianity & Married & $\mathrm{BSc}$ & Unemployed & Breast & Over 2 years \\
\hline 3 & 32 & Islam & Married & NCE & Unemployed & Breast & 4 years \\
\hline 4 & 56 & Christianity & Married & BSC & Civil servant & Breast & Over 5 years \\
\hline 5 & 44 & Christianity & Married & Pry six & $\begin{array}{l}\text { Self- } \\
\text { employed }\end{array}$ & Breast & 5 years \\
\hline 6 & 55 & Christianity & Married & NCE & Civil servant & Breast & 6 years \\
\hline 7 & 24 & Christianity & Single & BSc & Unemployed & Breast & 4 years \\
\hline 8 & 48 & Islam & Married & Pry six & $\begin{array}{l}\text { Self- } \\
\text { employed }\end{array}$ & Breast & Over 6 years \\
\hline 9 & 68 & Christianity & Married & $\mathrm{BSc}$ & Civil servant & Cervical & 9 years \\
\hline 10 & 62 & Christianity & Married & Nil & $\begin{array}{l}\text { Self- } \\
\text { employed }\end{array}$ & Ovarian & 10 years \\
\hline 11 & 51 & Christianity & Married & SSCE & $\begin{array}{l}\text { Self- } \\
\text { emploved }\end{array}$ & Endometrial & $41 / 2$ years \\
\hline 12 & 64 & Christianity & Married & BSc & Civil servant & Cervical & 5 years \\
\hline 13 & 51 & Christianity & Married & SSCE & $\begin{array}{l}\text { Self- } \\
\text { employed }\end{array}$ & Breast & 6 years \\
\hline 14 & 58 & Christianity & Married & BSC & Civil servant & Breast & 5 years \\
\hline 15 & 54 & Christianity & Married & $\mathrm{BSc}$ & Retrenched & Breast & Over 4 years \\
\hline 16 & 44 & Christianity & Married & $\begin{array}{l}\text { Secondary } \\
\text { school drop } \\
\text { out }\end{array}$ & $\begin{array}{l}\text { Self- } \\
\text { employed }\end{array}$ & Breast & 6 years \\
\hline 17 & 53 & Christianity & Married & NCE & Unemployed & Breast & 7 years \\
\hline 18 & 61 & Christianity & Married & $\begin{array}{l}\text { Pry school } \\
\text { dropout }\end{array}$ & $\begin{array}{l}\text { Self- } \\
\text { employed }\end{array}$ & Breast & 7 years \\
\hline 19 & 59 & Christianity & Married & NCE & Civil servant & Cervical & Over 3 years \\
\hline 20 & 62 & Christianity & Married & Pry six & $\begin{array}{l}\text { Self- } \\
\text { employed }\end{array}$ & Breast & 9 years \\
\hline
\end{tabular}


American Journal of Health, Medicine and Nursing Practice

ISSN 2520-4017 (Online)

Vol.6, Issue 3, pp 1 - 24, 2021

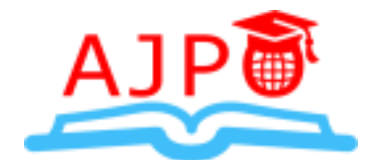

www.ajpojournals.org

\subsection{Thematic Analysis of the Participants' Interview Transcripts}

From the analysis of the participants' interview transcripts, the lived experiences of persons with gynecological cancers emerged in themes as follows:

Table 4.2 Themes that emerged from Participants' Interview Transcripts

\begin{tabular}{|l|l|}
\hline S/N & THEMES \\
\hline 1 & Ignoring the initial warning signs \\
\hline 2 & Reliance on unprofessional help and spiritual interventions \\
\hline 3 & Feeling of uncertainty and sense of vulnerability \\
\hline 4 & Bodily changes and altered body image \\
\hline 5 & The burden of chemotherapy \\
\hline 6 & Financial/economic hardship \\
\hline 7 & Counting the losses \\
\hline 8 & Dealing with the community and family-based stigma \\
\hline 9 & Cancer as a spiritual attack \\
\hline
\end{tabular}

\section{Theme 1: Ignoring the Initial Warning Signs}

The stories of women with cancer of the reproductive system are characterized by accounts of ignorance about early warning signs of cancers. Participants in this study expressed that, although they had noticed some warning signs of cancer, they ignorantly disregarded them. Some of these warning signs were initially perceived to be minor and wouldn't constitute major health problems, but eventually, these signs emerged into a life-changing health condition. For example, participants $1,2,3$, and 15 had observed the warning signs some years earlier but ignored them:

"I knew I was having a little discomfort but I didn't pay any attention to it, though it wasn't a big deal then...I felt some pains, peppery sensation on my breast, I assumed the pain was because I was still having my bra on, so I ignored it for a long time. "Respondent 1

"I noticed since 2011 that I had a lump on my left breast which I saw as nothing because it wasn't painful. My people advised I visit the hospital but I refused. 'Respondent 2

"I noticed since 2011 that I had a lump on my left breast which I saw as nothing because it wasn't painful. My people advised I visit the hospital but I refused. '’Respondent 3

Although evidence has shown that breast cancer is one of the leading causes of cancer-related deaths in Nigeria, the findings of this study show that women are still ignorant about the early 
American Journal of Health, Medicine and Nursing Practice

ISSN 2520-4017 (Online)

Vol.6, Issue 3, pp 1 - 24, 2021

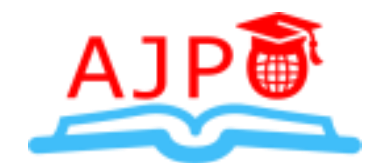

www.ajpojournals.org

signals of breast cancer. From the experiences of the participant, they probably would have paid more attention if the symptoms included pain. However, they expressed the fact that pain was not part of their initial warning signs which made them disregard other unusual appearances on their breasts.

According to Respondent 13: "since 2015, I noticed a lump in my left breast but it wasn't painful, so I ignored it" unfortunately, by the time pain becomes pronounced, other worrying symptoms are already manifesting."

"It's been about seven years since I have been noticing a sharp pain in my right breast, after a while, I noticed milk was coming out of the breast. 'Respondent 18

\section{Theme 2: Reliance on Unprofessional Help and Spiritual Interventions}

There seemed to be a great conflict or paradox between the adoption of orthodox treatment and the use of some unscientific measures. Many patients tended to use other forms of spiritual and traditional remedies in combination with conventional hospital treatment. Over-reliance on patients on spiritual and traditional healing measures has compounded the cancer situation in Nigeria as many patients would discontinue their conventional cancer treatment in search of a spiritual solution. Most cases of late diagnosis and treatment were as a result of the belief that their conditions are beyond what hospital treatment can cure and requires a "more potent" form of treatment such as intensive prayer rituals and seeking the help of a spiritualist or a sorcerer. Some patients explained their experiences:

"...we were told to press our breast before going to bed so that the hard part of the breast can be softened." Respondent 1

"At this point, I went back home and told my husband everything. We both agreed that I shouldn't go back to the hospital. Later I went for deliverance in our church. 'Respondent 2

Unfortunately, some patients who had already started chemotherapy treatment did not believe in the efficacy of the treatment. Instead, they abandoned their treatment and relied on prayers and other rituals. This is exemplified in the narratives of Respondent 2: "I decided not to go back to the hospital. I didn't take any treatment at all; I was going to the mountain to pray. The spot that was cut open on the breast started looking somehow."sRespondent 2

While respondent 2 started the chemotherapy before withdrawing, other participants did not take up the treatment at all and relied absolutely on prayers and spiritual rituals.

"I didn't take any treatment at all; I was going to the mountain to pray. The spot that was cut open on the breast started looking somehow. The breast had an open wound which I started treating at home with herbs... I went to the hospital and a lump was discovered. I got very angry and went back home." Respondent 2

"Our Islamic clerics were taking care of me with Holy water, soon the left breast had a big open wound which started smelling bad and the second breast (right breast) start paining and peppering me. "'Respondent 3

Many patient-reported that their late diagnosis was chiefly because they felt their conditions were exclusively spiritual that led them to seek spiritual solutions and use traditional products. It 
American Journal of Health, Medicine and Nursing Practice

ISSN 2520-4017 (Online)

Vol.6, Issue 3, pp 1 - 24, 2021

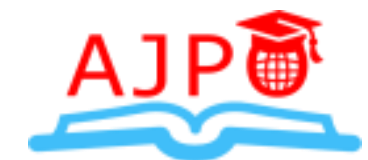

www.ajpojournals.org

was when their conditions persisted or became worse that they realized the need to seek medical help in the hospital.

"I came to the hospital after two years because I initially thought it was an attack from the new wife my husband had just taken. I had visited many local healers but there was no improvement, rather it was getting worse." Respondent 8

"I noticed pains that are peppery in nature in my private part. I went to the herb seller who has been known to my family for a long, she prepared concoctions for me which I used for about 8 to 9 months, with no improvement, instead, I started having foul-smelling discharge, I had to go to the hospital in October 2017." Respondent 11

"The breast had wound and I started treating it with herbs, it got a little better till around November 2016. In early 2019, I noticed I was feeling uncomfortable in my right breast, I went back to the hospital and I was told there was a lump on the breast. "Respondent 13

\section{Theme 3: Feeling of Uncertainty and Sense of Vulnerability}

One common experience among all the participants was that they were quick to ask the physician if chemotherapy would cure them. The entire participants were uncertain of what to expect after their cancer diagnosis and relied on the healthcare workers for recommendations making them vulnerable. According to them, immediately the physician announced their cancer diagnosis, this was always followed by a recommendation for chemotherapy by the doctors. In response, the participants would immediately ask about the certainty of the efficacy of chemotherapy. Unfortunately, the response they received did not match their expectations when the doctors replied that chemotherapy would not cure cancer but prevent it from spreading. Throughout the narratives of the participants, feelings of uncertainty and a sense of vulnerability were perceived.

"The doctor explained that I needed to start chemotherapy immediately; I asked if the Chemotherapy cures cancer, the doctor answered no. He said the chemo will destroy the cancer cells that might have gone to my armpit before a major surgery can be carried out. I was scared to death and my blood pressure became high due to this. 'Respondent 1

"The doctor further explained that I had to start Chemotherapy sessions immediately, I asked if Chemotherapy cures cancer, the Doctor said no but it will stop the cancer cells from spreading. "Respondent 2

"The doctor further explained that I need to start chemotherapy sessions; I asked if the chemotherapy cures cancer but the doctor said no but it will prevent the spread of the cancer cells. "'Respondent 4

The participants expressed their disappointments when they narrated that there was no appreciable improvement in their conditions even after the courses of chemotherapy with its associated side effects. This also made them more vulnerable:

"The doctor said I needed to start chemo session almost immediately I asked if it will cure cancer and the doctor said no and I started, after three sessions without any visible improvement, I went for surgery and the breast was amputated in February 2015. 'Respondent 6. 
American Journal of Health, Medicine and Nursing Practice

ISSN 2520-4017 (Online)

Vol.6, Issue 3, pp 1 - 24, 2021

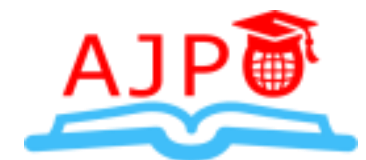

www.ajpojournals.org

"The doctor advised I started chemotherapy sessions which I asked if the chemo will cure cancer but unfortunately the doctors said no. I have come for six sessions of the chemotherapy without any improvement. 'Respondent 7

"Doctor further explained that I need to start Chemotherapy; I asked if it cures cancer but the doctor said no. I have taken four Chemotherapy and there was none visible improvement. "Respondent 14

"The Doctor explained that I needed to start Chemotherapy; I asked if it cures cancer and he said no. I came for Chemotherapy four consecutive times but there was no visible improvement." Respondent 17

After undergoing the full courses of chemotherapy with no positive improvements, the participants were discouraged and decided not to return to the hospital. Respondent 1 says: "after this, I got tired of everything and I stopped going to the hospital". In addition to this, other participants narrated:

"At this point, I told my husband I want to go back to the hospital to explain to the doctor. In January 2018, I went back to the hospital, I was told by the doctor that the condition of the breast had become worsen and I needed another round of Chemotherapy. I felt like going back home at this point because of how badly I used to feel after each session of the Chemotherapy." Respondent 2

\section{Theme 4: Bodily Changes and Altered Body Image}

One encounter that was meaning in their lived experiences was the concept of the lived body, which portrays their experiences with the bodily changes and altered body image. Cancers of the gynecological system do not only affect the psychological wellbeing but also have an impact on their perception of body image. Participants in this study narrated their ordeals with how their bodies began to undergo some unexpected changes with many unpleasant manifestations. Interestingly, they were more relaxed when they didn't have open wounds than when the open wounds appeared on their breasts and other affected sites. For example, the story of respondent 2 shows how the patients' emotional stability was influenced by the presence or absence of open wounds:

"There was no open wound on the breast so this made me relax and rest. The only spot on the breast was where it was surgically cut open to take a sample for the test. I was instructed to be cleaning it with the methylated spirit which I was doing, after a while, the site started looking somehow.'Respondent 1

"However, things began to change for participant 1 when some open wounds began to appear on her breast with some pungent: "The spot that was cut opened has developed into a wound and it has started smelling bad...the site looks unpleasant and it has started smelling. "'Respondent 1

The oozing out of "milk-like liquid" and foul odor from the breast constituted a major source of concern and fear to the participants with breast cancer. Some of them also highlighted how it became impossible for them to wear "bras" and they had to pack the amputated breast space with pieces of clothing: 
American Journal of Health, Medicine and Nursing Practice

ISSN 2520-4017 (Online)

Vol.6, Issue 3, pp 1 - 24, 2021

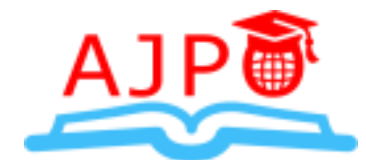

www.ajpojournals.org

“Around June 2017, I noticed I started feeling uncomfortable, peppery pain sensation on the breast, I intensified my prayers and hope in God. One day, my husband and I were trying to make love and he was sucking my breast, liquid-like milk gushed out into his mouth, since then I started visiting EKSUTH for tests and proper diagnosis. The odor from the breast became bad and embarrassing, blood was coming out and it stained my clothes, I started having diarrhe and I couldn't eat. ' Respondent 2

"It's been almost seven years since I noticed that my left breast is paining me, the peppery sensation was what I felt, later I noticed fluid like milk started coming out, ...after some months, I came back to the hospital but the breast already had wound, blood was coming out and it smelled terrible. "Respondent 8

"In July 2010, I noticed I was excessively adding weight, I was having abdominal pains and lots of discharge from my vagina. The discomfort got worse and I had to visit the General

Hospital in my hometown.'Respondent 15

"It hasn't been easy for me to wear a bra on one breast and stuff the other space with clothes and I have no strength to do much since then. "Respondent 16

\section{Theme 5: The Burden of Chemotherapy}

Chemotherapy is one of the treatment options recommended by physicians the moment a person is diagnosed with cancer. While evidence suggests that chemotherapy may be effective in treating certain kinds of cancer, findings of this study have shown that the participants had negative experiences with their chemotherapy sessions. None of the participants discontinued chemotherapy due to financial issues; however, non-compliance with chemotherapy sessions was majorly due to the adverse effects on the body. For example, many of the participants complained of severe nausea and vomiting, in addition to major episodes of diarrhea, abdominal pain, and generalized body weakness. Some patients would prefer having cancer lesions to the unimaginable adverse reactions of chemotherapy.

Unfortunately, some participants expressed their dissatisfaction that despite the courses of chemotherapy, their conditions did not improve significantly:

"The doctor said I had to take another round of chemotherapy that the condition of the breast has worsened. I wasn't happy because of how I always feel after each session of chemotherapy. "'Respondent 1

"If I go for it on Friday, I will be extremely weak, my stomach will be upset, I will feel like vomiting. The chemotherapy I had when the breast already has wound was worse." Respondent 1

"Any day I went for the Chemotherapy, I was usually weak, my stomach will be upset and I will be feeling so much discomfort as if I want to vomit, as these are far better than when there was wound on the breast."'Respondent 1

Initially, many of the patients inquired immediately if there are chances that the chemotherapy would cure cancer. But the doctor said no but it will prevent the cancer cells from spreading any further: 
American Journal of Health, Medicine and Nursing Practice

ISSN 2520-4017 (Online)

Vol.6, Issue 3, pp 1 - 24, 2021

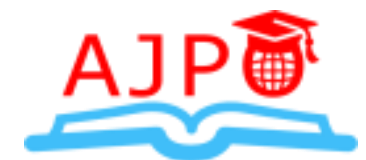

www.ajpojournals.org

"The doctor advised that I start chemotherapy, I asked if it cures cancer but the doctor said no but it will prevent the cancer cells from spreading any further. I went for four sessions of chemotherapy consecutively; it didn't go well with me at all.' Respondent 3

"After four sessions of the chemotherapy without any visible improvement, the breast was surgically removed as I couldn't cope with the effects of the chemotherapy like stomach ache, diarrhea, loss of hair, changes in skin color and lots more.'Respondent 4

"Hmm, the side effects of the chemotherapy like stomach ache, loss of hair, diarrhea, and skin discoloration and so on were what I had to go through."'Respondent 6

The gastro-intestinal side-effects were of utmost concern to the participants. Many of them complained of diarrhea, nausea and vomiting at all times. And all these side-effects constituted a major percentage of the reasons for not complying with chemotherapy sessions:

"I realized the chemo was making me uncomfortable anytime I had it, I will be feeling like vomiting but I won't be able to do so and I will be extremely weak. '’Respondent 8

“Chemotherapy, I won't be able to eat, I will be feeling like vomiting, at a time, I started losing my hair; I was always weak and lost a lot of weight. 'Respondent 1

"I noticed the chemotherapy was affecting me negatively, after taking it I used to have diarrhea, I will be feeling like vomiting but nothing will come out and I will be extremely weak. I can't just describe all I used to feel but I had to come back to the hospital after some months. 'Respondent 18

\section{Theme 6: Financial/Economic Hardship}

This theme contains the unpleasant experiences and economic hardships encountered by patients and relatives due to cancer, which includes the nature and content of experiences of financial suffering by the cancer patients being hospitalized and treated in these hospitals. The participants reported the problem of high cost of cancer treatment and the resultant economic hardship among patients and families. Although, some patients opted out of chemotherapy as captured in their narratives, some of these decisions were made due to severe financial constraints brought about by the exorbitant cost of cancer treatment. Some participants lamented that they had to sell all their properties in order to be able to pay part of the treatment fees. Patients complained of the different ways cancer has affected their financial status and caused untold hardship. Responses such as "My Finances has been negatively affected" and "I became financially broke" are common narratives obtained from the participants. Because cancer and its treatment subject patients to several unpleasant symptoms and experiences, the patients usually are not able to work and make some funds to finance their treatment. Consequently, most patients rely heavily on family and relatives for financial support. However, sometimes the support from family and relatives goes beyond financial aid and extends to physical and emotional support. For example, a patient describes how her family was involved in finding solutions to her cancer illness

“Cancer illness has eaten deep into my family's finances, money for chemotherapy, my diet was changed and it cost a lot at the end. 'Respondent 4 
American Journal of Health, Medicine and Nursing Practice

ISSN 2520-4017 (Online)

Vol.6, Issue 3, pp 1 - 24, 2021

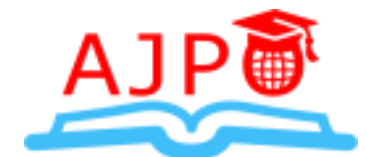

www.ajpojournals.org

"At times, my children had to go through hard labor of working with bricklayers before I could get money for the Chemotherapy treatment and feeding, even the Chemotherapy itself wasn't a pleasant journey for me. "Respondent 11

Most of the times, the multiple chemotherapy sessions and food restrictions contributed to the financial hardship encountered by these patients. Some participants go as far as taking a loan from family and friends in order to pay for treatment. However, since the treatment is an ongoing process, they were not able to pay up, which led to more problems.

"Cancer ailment has affected my family's finances negatively, the money I spent on Chemotherapy and the type of food I eat is much. "'Respondent 17

The patient's economic hardship is seen in their daily care. If the patient does not have a good economic situation, the patient does not only have to worry about his/her disease, but also about the treatment costs at the hospital. In fact, not only the patient has to worry, the family bears the worries until the patient is prepared to confront and deal with all the facts

"I borrowed money from a family friend and I was unable to pay back this loan because I was on admission at the hospital receiving chemotherapy. The person brought two policemen to arrest me, but when the policemen saw me, they started crying and I lost all hopes that very day. 'Respondent 19

\section{Theme 7: Counting the Losses}

Cancer of the female reproductive system is associated with many losses. From the account of participants, persons affected with cancer are bothered about how their belongings, including family and friends, disappeared within a short period. These loses are significant themes that emerged from their narratives. While there were material loses, the loss of human connectedness seemed quite significant. Participants described a situation whereby some husbands abandon their wives after undergoing mastectomy with the excuse that their wives are no longer attractive to them without one or both breast(s). For example, respondents 1, 7, 12 and 4 expressed sadness when they narrated how their cancer diagnosis caused them to lose their husbands, children and parents. While respondent 7 lost her father due to a heart attack caused by the news of her cancer diagnosis, respondents 1, 5, 7, 12 and 14 experienced losses due to rejection by families and friends. Interestingly, other forms of losses observed in this study were feelings of loss from the removal of either one or both breasts.

\section{"I lost respect at home and amongst my in-laws. 'Respondent 1}

"According to the Islamic rites, my husband is entitled to take up another wife which I'm anticipating may happen sooner than later. "Respondent 1

"My husband left me because my two breasts had been cut off, he called me a man and left with lots of my belongings, hmmmm... I had to live in a room apartment because I was financially incapacitated. 'Respondent5

"My father suffered heart attack and died when I was diagnosed of breast cancer, my father, a rare gem and the breadwinner of the family was lost just like that...its worse because my two 
American Journal of Health, Medicine and Nursing Practice

ISSN 2520-4017 (Online)

Vol.6, Issue 3, pp 1 - 24, 2021

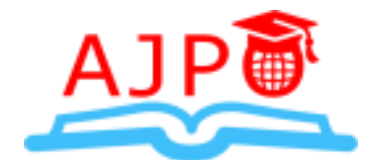

www.ajpojournals.org

breasts were cut off and I can't think of anything worse than this. I have lost my self-esteem due to this, my boyfriend left so also my friends. 'Respondent 7

Respondent 1 expressed loss of respect and human dignity. Respondents 9 and 12 were particularly concerned about their properties which they sold in order to meet up with their cancer treatment obligations.

"I had spent a lot of money and sold many properties due to this aliment but I thank God for the gift of life, my friends and families neglected me but God said we should be thankful in all situations. 'Respondent 9

"Being a retiree, I felt bad that I had to nurse cancer; I spent over $70 \%$ of my monthly stipend on my health. Two of my children had to drop out of the University for a whole year, so I won't lose my life; I have lost almost all my properties. 'Respondent12

The diagnosis of cancer caused a divorce between respondent 14 and her husband. This event did not only cost her husband and marriage, but her two children were also taken away from her. In her experience, she had suffered this trauma for over 4 years and on.

"This has been a traumatic experience of over 4years. The announcement of my diagnosis to my husband led to our divorce process and he went away with our two children, 'As I speak with you, I don't know their where about. "Respondent 14

\section{Theme 8: Dealing with Community and Family-Based Stigma}

Although cancer diagnosis no longer places an individual into a collectively understood stigmatized category in the global world, some patients' in this study have narrated their own story of how they experienced some forms of stigmatization and labeling. Most forms of stigmatization found in this study are based on people's assumption that anybody who has cancer is suffering from a spiritual attack or is evil. According to the participants, friends and relatives with such perceptions tend to withdraw or separate themselves from the patients:

"The news of my ailment had gone round the town, I became a topic of gossip even though I had no friends but neighbors around were suspecting and assuming the nature of my ailment. Many people were asking why my skin color became dark all of a sudden because I used to be light in complexion. Those close to my mummy advised her to take very good care of me. 'Respondent 1

"While all the gossips were ongoing, I had no friend or enemies, I had no one to talk to or explain what was wrong with me. Finally anchor, it got to a point I felt like committing suicide. It has affected me adversely psychologically and my husband too. I am yet to have a child, my husband's family said I had familiar spirit and that I vowed never to have any child in this world. "Respondent 2

For participant 4, the loss of one of her breasts brought significant loss of self-esteem unto her. Consequently she was no longer motivated to go to work and interact with colleagues. Similarly, participant 5 and 7 received derogatory comments from their partners after they lost their breasts to cancer. According to them, their partners described them as men because their breast had been removed. 
American Journal of Health, Medicine and Nursing Practice

ISSN 2520-4017 (Online)

Vol.6, Issue 3, pp 1 - 24, 2021

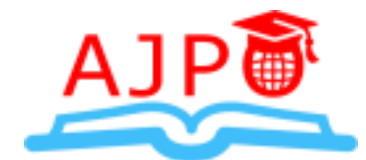

www.ajpojournals.org

"My husband left me because my two breasts had been cut off; he called me a man and left with lots of my belongings. In fact this cancer of a thing has made me a topic of gossip at work and in the neighborhood. I am feeling much better but I have lost a lot that can't ever be replaced." Respondent5

"It's worse because my two breasts were cut off and I can't think of anything worse than this. I have lost my self-esteem due to this, my boyfriend left so also my friends. 'Respondent7

"Firstly, my husband sent me packing, our neighbors labeled me a witch and I can barely do anything since them. 'Respondent8

Although some of the participants expressed that they had the need to talk to people and ask burning questions about their conditions and treatment, they were too ashamed to make their conditions and concerns known to the public for fear of stigma. In fact, participant 4 became too ashamed to go to work for fear of stigma and discrimination. In the same vein, participant 11 couldn't handle the enormous shame to the extent that she had to move to a totally different neighborhood where nobody knew them.

"Changes like having one breast, this deformity made me really sad, my left hand became painful since the breast has been cutoff, secondly I became ashamed of my abseentism at work, they have been gossiping about me." Respondent 4

"There are rumors around the neighborhood; many people started asking me how come my skin became so dark because I used to be light in complexion... but later I have to move with my children to another neighborhood where we were not known. 'Respondent11

"People who knew about my ailment and that of my mother started referring to me as 'like mother like daughter'. I won't say more than this. "Respondent 17

\section{Theme 9: Cancer as a Spiritual Attack}

The patients believed that their condition was an attack sent from wicked people. Commonly, people who believe their conditions are an attack tends to seek spiritual and supernatural solutions from native or witch doctors:

"I have been told by my Pastor since I was in Secondary School that an attack was targeted at me and since then I've been praying that God should avert it. It's been precisely 18 years, when it was 2017, I knew the attack had finally manifested in my body, left breast precisely. I called my pastor immediately I noticed the attack and I started praying fervently for healing and that the attack to go back to the sender. Around June 2017, I noticed I started feeling uncomfortable, peppery pain sensation on the breast, I intensified my prayers and hope in God. "Respondent 2

"In 2013, I had a spiritual attack. In 2015, a lump like beans developed on my breast and I went to hospital, I was examined and the bean sized lump was discovered which wasn't painful... I came back six weeks later, collected the test result and the doctor said I had cancer. Then I remembered I had a spiritual attack in 2013 so I knew this was its manifestation. "Respondent 4

Most cases of late diagnosis and treatment were as a result of the belief that their conditions are beyond what hospital treatment can cure and requires a "more potent" form of treatment such as 
American Journal of Health, Medicine and Nursing Practice

ISSN 2520-4017 (Online)

Vol.6, Issue 3, pp 1 - 24, 2021

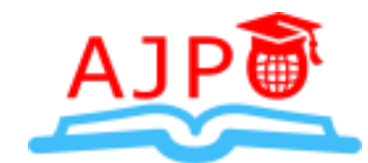

www.ajpojournals.org

intensive prayer rituals and seeking the help of a spiritualist or a sorcerer. A participant explains her experience:

"I came to the hospital after two years because I initially thought it was an attack from the new wife my husband had just taken. I had visited many local healers but there was no improvement, rather it was getting worse."'Respondent 8

"In 2012, I noticed I was feeling pains in my breast my husband said maybe it was African pepper that I was attacked with, later milk-like liquid started coming out. 'Respondent 20

\subsection{Discussion of Findings}

\section{Theme 1: Ignoring the Initial Warning Signs}

Participants in this study expressed that, although they had noticed some warning signs of cancer, they ignorantly disregarded them. Some of these warning signs were initially perceived to be minor and wouldn't constitute major health problems, but eventually, these signs emerged into a life-changing health condition.

This is similar to the study by Bonsu and Ncama (2019) who reported that women with gynecological cancers delayed presentation due to poor recognition and appraisal of breast cancer symptoms. For example, a painless breast lump was considered not serious until a sensory symptom appears, as most women labeled painless breast lump as not serious and dangerous, normal or not a disease. In some women too, the heaviness of the breast was attributed to hormonal changes such as ovulation period or signs of pregnancy.

\section{Theme 2: Reliance on Unprofessional help and Spiritual Interventions}

Indeed, it is almost impossible to divorce our patients' healthcare from their spirituality. Cancer patients have been reported to use a variety of religious and spiritual resources, such as personal faith and prayer, relationship with God, prayers from fellow church members, pastor/priest or leader of faith, reading the bible, attending religious services, meditation, spiritual retreats as means of coping with their health conditions. Here is a patient's account

"At this point, I went back home and told my husband everything. We both agreed that I shouldn't go back to the hospital. Later I went for deliverance in our church. ".

This is in line with a study by Asuzu et al. (2019) who reported a similar theme as patients stated that the cure for cancer was through prayers to God and use of herbs and stated that reasons for using traditional healers include financial consideration, convenience, incorporation of their spiritual beliefs and recommendation by others and need for collaboration between orthodox medicine and traditional healers. Asuzu et al. (2019) further reported that the majority of the patients believe traditional healers who use herbs can cure cancer; others use a mix of faith-based healing therapy with the orthodox treatment and all the patients unanimously believe in the efficacy of prayers in curing cancer (Asuzu, Akin-Odanye, Asuzu, \& Holland, 2019).

Another study by Movafagh et al. (2017) corroborated this theme reporting that religion and spirituality are resources that are regularly used by patients with cancer coping with diagnosis and treatment. Additionally, detailed information has been evaluated, showing that a large range of complementary/ alternative medicine types was used by females with breast cancer such as 
foods, herbs, and vitamins as well as prayer and mind healing meditation (Movafagh, Heidari, Abdoljabbari, Mansouri, Taghavi, Karamatinia et al., 2017).

Ogunkorode et al. (2021) also reported that most patients perceived cancer to be caused by spiritual forces, which can only be cured by traditional healers because Western medicine has been seen to be ineffective in managing such illnesses. This perception was often fueled by the fact that most cancer patients die even after receiving orthodox Western medical care. Therefore, to secure all the possible benefits and make sure they are not losing out on anything that might help in managing their breast problems; the people try alternative treatments first or use them in combination with Western biomedical practice.

\section{Theme 3: Feeling of Uncertainty and Sense of Vulnerability}

Findings showed that the entire participants were uncertain of what to expect after their cancer diagnosis and relied on the healthcare workers for recommendations making them vulnerable. Unfortunately, the response they received did not match their expectations when the doctors replied that chemotherapy would not cure cancer but prevent it from spreading. Throughout the narratives of the participants, feelings of uncertainty and a sense of vulnerability were perceived. This is in line with the narratives of the American Cancer Society (2011) that many cancer survivors find that they feel unsure about many aspects of their lives and treatment. This is called living with uncertainty. However, living with uncertainty can also be very difficult and upsetting. Some persons with gynecological cancers think that if they aren't certain about most things in their life, then bad things are likely to happen.

\section{Theme 4: Bodily Changes and Altered Body Image}

Cancers of the gynecological system do not only affect psychological wellbeing but also have an impact on their perception of body image. Participants in this study narrated their ordeals with how their bodies began to undergo some unexpected changes with many unpleasant manifestations. This is in line with the study of Fingeret, Teo, and Epner (2014) who opined that body image issues affect a wide array and also constitute a critical psychosocial issue for cancer patients as they often undergo significant changes to appearance and functioning.

The study is also supported by Rowe (2020) who said that body image is an important concern for cancer patients. It has been noted that the physical signs of disease or its treatment can be a constant reminder of the reality of cancer, leading to adaptation difficulties or the emergence of emotional frailty. In breast cancer, body image has been conceptualized to include both disfigurement and dysfunction and is affected by pre-existing patient characteristics, social factors, environmental factors, and time from treatment. Resultant body image has then been found to affect patients' social and psychological outcomes, as well as the general quality of life. These consequences include higher rates of depression, anxiety, and difficulty coping.

\section{Theme 5: The Burden of Chemotherapy}

The findings of this study have shown that the participants had negative experiences with their chemotherapy sessions. Non-compliance with chemotherapy sessions was majorly due to the adverse effects on the body. For example, many of the participants complained of severe nausea 
and vomiting, in addition to major episodes of diarrhea, abdominal pain, and generalized body weakness.

This was in line with the study by Chui (2019) that although chemotherapy has significantly improved overall survival, patients still experience a wide range of physical and psychological symptoms that impact their quality of life. Chemotherapy-induced hair loss remains greatly feared, with a negative impact on the well-being of many cancer patients. Cancer and chemotherapy-induced poor appetite is usually the result of taste changes, mouth sores, nausea and vomiting, increased satiety, medication side effects, pain, fatigue, depressed mood, and anxiety.

Ogunkorode et al. (2021) further reported that women with gynecological cancers experienced increased suffering from chemotherapy. This was related to the side effects of chemotherapy as most participants spoke of the severity of these treatments. The effects of the chemotherapy made a forty-three-year-old participant feel afraid and she added, "The illness is not as severe on the body as the drug." Some participants described how they felt after chemotherapy. "if I take that chemo three days ... I will be feeling as if the end has come" (a forty-two-year-old participant); and "I have some reactions ... like vomiting, fatigue, unable to eat, unable to pooh, and just that" (a forty-nine-year-old participant).

These findings are also consistent with findings from Maree and Mulonda (2015) which indicated that the side effects of chemotherapy resulted in negative experiences associated with various side-effects, which added to the women's sufferings. These experiences could influence the health-seeking behavior of patients with gynecological cancers. In another study, Gurung and Pandey (2015) identified the five most troublesome physical side effects of chemotherapy reported by persons with gynecological cancers were: loss of appetite, feel constantly tired nausea, constipation, and numbness in limbs. Constipation and numbness are in contrast with the findings of this study.

\section{Theme 6: Financial/Economic hardship}

In Nigeria, where the financial/economic implications of gynecological cancers are borne through out-of-pocket payments, the burden of treatment can become massive. Participants expressed their hardships with statements such as: "My Finances has been negatively affected" and "I became financially broke" are common narratives obtained from the participants"

This theme contains the unpleasant experiences and economic hardships encountered by patients and relatives due to cancer, which includes the nature and content of experiences of financial suffering by the cancer patients being hospitalized and treated in these hospitals. Some participants lamented that they had to sell all their properties to be able to pay part of the treatment fees. Patients complained of the different ways cancer has affected their financial status and caused untold hardship. This is supported by the study of Liang et al. (2019) that financial distress affects over half of gynecologic cancer patients starting a new line of treatment and this associated with material hardship.

Ogunkorode et al. (2021) further corroborated the findings in the present study as patients with gynecological cancer reported difficulty in paying for treatments and the burden of procuring 
medications that are too expensive. A fifty-four-year-old participant explained what could happen to people with not enough money to treat the disease: "If one does not have capital and one does not have anybody to give financial support, which is what kills a person who has this illness. "These hardships often lead patients to discontinue treatment or sell possessions and properties to accommodate the huge financial burden. As a forty-three-year-old participant revealed, "Money is a big issue," adding that "although most women want to continue with their breast cancer treatment, the cost of treatment is too high." The cost of cancer treatment and care constitutes major challenges in seeking health care (Ogunkorode et al., 2021).

Similar findings were also reported by Pruitt et al. (2015) in a qualitative study of the social barriers to the diagnosis of breast cancer in a teaching hospital in Nigeria, who further stated that indigents are often led to seek alternative treatment options due to lack of financial resources to bear this burden (Pruitt, Mumuni, Raikhel, Ademola, Ogundiran, Adenipekun. et al., 2015).

\section{Theme 7: Counting the Losses}

This is similar to the study by Ogunkorode et al. (2021) who reported that women with gynecological cancers end up selling their possessions and properties to accommodate the huge financial burden associated with the treatment.

\section{Theme 8: Dealing with Community and Family-Based Stigma}

From the study, some persons in this study have narrated their own story of how they experienced some forms of stigmatization and labeling. Most forms of stigmatization found in this study are based on people's assumption that anybody who has cancer is suffering from a spiritual attack or is evil. According to the participants, friends and relatives with such perceptions tend to withdraw or separate themselves from the patients.

This is supported by the study of Fujisawa and Hagiwara (2015) that cancer stigma not only influences strangers'/acquaintances' reactions but also family members'spouses' reactions toward the patients with cancer. The study revealed also that greater self-reported shame among patients with cancer was associated with decreased amount of time spent to talk about their relationship with the family/spouse and lower marital satisfaction.

Similar findings about stigma among patients with gynecological cancers have also being reported. For example, Assaf et al. (2017) reported that patients with breast cancer experienced stigmatization; Maree and Mulonda (2015) also reported stigmatization among Zambian women with advanced stages of gynecological cancers, and Meacham et al. (2016) explored stigma as a barrier to participation in breast cancer care in Kampala Uganda. All these studies observed that stigma was associated with the diagnosis of breast cancer. The women in the studies reported that they lost their social relationships and their friends, and their family stopped visiting them. These reactions led them to isolate themselves from people who according to the women, "do not understand the disease" (Assaf, Holroyd\& Lopez, 2017; Maree \& Mulonda, 2015; Meacham, Orem, Nakigudde, Zujewski, \& Rao, 2016).

The stigma experienced by patients with gynecological cancer in a study by Ogunkorode et al. (2021) was related to the cultural myths and taboos surrounding the illness. Such taboos and myths include the perception that breast cancer is always fatal; that mastectomy mutilates the 
human body and renders a woman incomplete; the concern that if cancer is cut into, the cancer will spread immediately to other parts of the body; and that those whose breast is cut off will die within a short time (Movafagh et al. 2017).

\section{Theme 9: Cancer as a Spiritual Attack}

This is in line with a study by Asuzu et al. (2019) who reported a similar theme as patients reported cancer as caused by a satanic attack. Asuzu et al. further reported that while some respondents said "I wouldn't know because I am not a medical practitioner"; others said cancer could be caused by "ignorance and satanic attack", "diet and it could be an attack"; "demonic attack, overwork, and stress".

This finding is similar to those of Ogunkorode et al. (2021) who reported that many participants believed that breast cancer was a disease inflicted by the enemy, a spiritual attack, also called an arrow. The general belief was that a spiritual attack is a deliberate act of malice. It could also be inflicted by a traditional practitioner at someone else's request. Traditional healers and spiritualists also have the power to counter a spiritual attack. Such practitioners would return the arrow to the sender through prayers and other remedies (Ogunkorode, Holtslander, Ferguson, Maree, Anonson, \& Ramsden, 2021).

\subsection{SUMMARY, CONCLUSIONS AND RECOMMENDATION}

\subsection{Summary of Findings}

This study explores the lived experiences of persons with gynecological cancers attending Teaching Hospitals in Ekiti State. In order to achieve the objective of this study, a qualitative research design using phenomenological method was adopted by conducting individual interview among persons with gynecological cancers attending Teaching Hospitals in Ekiti State.

As seen in the various themes, experience of breast changes triggered an emotional response in the participants. The experience of worsening of symptoms increased the participants' physical and psychological reactions. Individual perceptions of having contracted a serious illness led to heightened level of threat, triggering participants' decision-making process to engage in health seeking.

\subsection{Conclusion}

As evidenced by the study, nine (9) themes emerged from the study ranging from ignoring the initial warning signs to cancer as a spiritual attack.

Persons with gynecological cancers in Teaching Hospitals in Ekiti State typically present in the hospital for the management at the advanced stages of their illnesses. Individual perception of gynecological cancer as a life-threatening illness that few people survive; cultural perception of cancer as a spiritual attack; altered body images; the financial challenges of cancer treatments; socio-cultural factors; and a desire to live influenced the participants' health-seeking behaviors. The need is great to support persons who have this illness and to educate the community comprehensively about issues relating to gynecological cancers etiology and its treatments.

Findings from this study can empower nurses and other gynecological cancer stakeholders to design and implement interventions that can enhance holistic assessment, management and care 
American Journal of Health, Medicine and Nursing Practice

ISSN 2520-4017 (Online)

Vol.6, Issue 3, pp 1 - 24, 2021

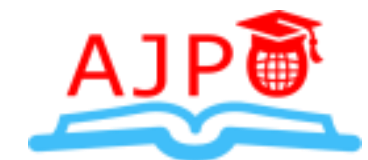

www.ajpojournals.org

delivery of this type of cancer in the region, thereby improving the survival rates for persons with the illness at large.

\subsection{Recommendation}

- $\quad$ The premise from this study, suggest the need to address individual perceptions about the causes of gynecological cancers.

- This study revealed that some participants faced the challenge of stigmatization. Therefore there is need to draw a supportive intervention by the government for affected persons.

- $\quad$ Mass sensitization of the general public through mediums such as social gathering, town meetings, and church gatherings about information relating to cancers affecting reproductive organs are needed.

- $\quad$ Nurses and health care professionals of health care should make time available to interact with persons with gynecological cancers to afford them the opportunity to disclose and address major point of concerns.

- Oncology nurses can inform affected persons on the need for early detection and likely expectations and outcomes before, during, and after specific treatment processes.

\section{References}

Abdollahimohammad, A., Firouzkouhi, M., \& Naderifar, M. (2018). Lived Experiences of Iranian Cancer Patients after Survival: A phenomenological research. Journal of Patient Experience 2019, Vol. 6(2) 164-168

Assaf, G. N., Holroyd, E., \& Lopez, V. (2017). Isolation and prayer as means of solace for Arab women with breast cancer: An in-depth interview study. Psycho-Oncology. https://doi.org/10.1002/pon.4402.

Asuzu, C.C., Akin-Odanye, E.O., Asuzu, M.C. \& Holland, J. (2019) A socio-cultural study of traditional healers role in African health care. Infect Agents Cancer 14, 15 (2019). https://doi.org/10.1186/s13027-019-0232-y

Binka C, Doku DT, Awusabo-Asare K. Experiences of cervical cancer patients in rural Ghana: An exploratory study. PLoS One. 2017 Oct 11;12(10):e0185829. doi: 10.1371/journal.pone.0185829. PMID: 29020099; PMCID: PMC5636100.

Bonsu, A.B. \& Ncama, B.P. (2019) Recognizing and appraising symptoms of breast cancer as a reason for delayed presentation in Ghanaian women: A qualitative study. PLoS ONE, 14(1), e0208773. https://doi.org/10.1371/journal. pone.0208773

Fingeret M.C, Teo I, Epner DE. Managing body image difficulties of adult cancer patients: lessons from available research. Cancer. 2014 Mar 1;120(5):633-41. doi: 10.1002/cncr.28469. Epub 2013 Nov 21. PMID: 24895287; PMCID: PMC4052456.

Fujisawa, D., Hagiwara, N. Cancer Stigma and its Health Consequences. Curr Breast Cancer Rep 7, 143-150 (2015). https://doi.org/10.1007/s12609-015-0185-0 
American Journal of Health, Medicine and Nursing Practice

ISSN 2520-4017 (Online)

Vol.6, Issue 3, pp 1 - 24, 2021

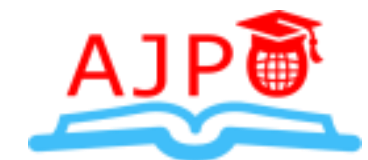

www.ajpojournals.org

Guenther J, Stiles A, Champion JD. The lived experience of ovarian cancer: a phenomenological approach. J Am Acad Nurse Pract. 2012 Oct;24(10):595-603. doi: 10.1111/j.17457599.2012.00732.x. Epub 2012 Apr 26. PMID: 23006018.

Gurung S, Acharya R, P. Perception of Side Effects of Chemotherapy among Cancer Patients in B.P. Koirala Memorial Cancer Hospital Bharatpur, Nepal. JCMS Nepal. 2015;11(4):1419.

Huang, H. Y., Tsai, W. C., Chou, W. Y., Hung, Y. C., Liu, L. C., Huang, K. F., Wang, W. C., Leung, K. W., Hsieh, R. K., \& Kung, P. T. (2017). Quality of life of breast and cervical cancer survivors. BMC women's health, 17(1), 30. https://doi.org/10.1186/s12905-017$\underline{0387-\mathrm{X}}$

Liang M.I, Pisu M, Summerlin S.S, Boitano T.K.L, Blanchard C.T, Bhatia S, Huh W.K. Extensive financial hardship among gynecologic cancer patients starting a new line of therapy. GynecolOncol. 2020 Feb;156(2):271-277. doi: 10.1016/j.ygyno.2019.11.022. Epub 2019 Nov 23. PMID: 31771866; PMCID: PMC7018550.

Maree, J. E., \&Mulonda, J. (2015). "My experience has been a terrible one, something I could not run away from": Zambian women's experiences of advanced breast cancer.

Muliira, R. S., Salas, A. S., \& O'Brien, B. (2017). Quality of Life among Female Cancer Survivors in Africa: An Integrative Literature Review. Asia-Pacific journal of oncology nursing, 4(1), 6-17. https://doi.org/10.4103/2347-5625.199078

Ogunkorode, Holtslander, Ferguson, Maree, Anonson, \& Ramsden (2021). Factors influencing the health-seeking behaviors of women with advanced stages of breast cancer in Southwestern Nigeria: An interpretive description study. International Journal of Africa Nursing Sciences, 14 (100273), 2214-1391. https://doi.org/10.1016/j.ijans.2020.100273.

Pruitt, L., Mumuni, T., Raikhel, E., Ademola, A.,Ogundiran, T., Adenipekun, A. et al. (2015). Social barriers to diagnosis and treatment of breast cancer in patients presenting at a teaching hospital in Ibadan, Nigeria. Global Public Health, 10 (3), 331-344. https://doi.org/10.1080/17441692.2014.974649.

Rowe, L., Vera, E., Acquaye, A. et al. The prevalence of altered body image in patients with primary brain tumors: an understudied population. J Neurooncol 147, 397-404 (2020). https://doi.org/10.1007/s11060-020-03433-8

Sekse R. J. T, Dunberger G, Olesen M. L, Østerbye M, Seibaek L. Lived experiences and quality of life after gynaecological cancer-An integrative review. J ClinNurs. 2019 May;28(910):1393-1421. doi: 10.1111/jocn.14721. Epub 2019 Jan 11. PMID: 30461101; PMCID: PMC7328793.

Sharma A, Saneha C, Phligbua W. Effects of Dyadic Interventions on Quality of Life among Cancer Patients: An Integrative Review. Asia Pac J OncolNurs [serial online] 2021 [cited 2021 Apr 29];8:115-31. Retrieved from: https://www.apjon.org/text.asp?2021/8/2/115/308310 
Stanton A.L, Rowland J.H, Ganz P.A. Life after diagnosis and treatment of cancer in adulthood: contributions from psychosocial oncology research. Am Psychol. 2015 FebMar;70(2):159-74. doi: 10.1037/a0037875. PMID: 25730722.

Tsai L.Y, Wang K.L, Liang S.Y, Tsai J.M, Tsay S.L. The Lived Experience of Gynecologic Cancer Survivors in Taiwan. J Nurs Res. 2017 Dec;25(6):447-454. doi: 10.1097/JNR.0000000000000229. PMID: 29023254.

Williams F, Jeanetta S.C. Lived experiences of breast cancer survivors after diagnosis, treatment and beyond: qualitative study. Health Expect. 2016 Jun;19 (3):631-42. doi: 10.1111/hex.12372. Epub 2015 May 7. PMID: 25953316; PMCID: PMC5029767.

Yaman, S., \& Ayaz, S. (2016). Psychological Problems Experienced by Women with Gynecological Cancer and How They Cope with It: A Phenomenological Study in Turkey. Health \& social work, 41(3), 173-181. https://doi.org/10.1093/hsw/hlw030. 